\title{
A Novel, Effective and Efficient Methodology for the $\alpha$-Iodination of Alicyclic Acids Using Molecular Iodine
}

\author{
PAWAN J. TAMBADE ${ }^{*}$ and SRINIVAS RAO PEDADA \\ Department of Chemistry, MVP Samaj's Arts, Commerce and Science College, \\ Nandgaon 423 106. Affiliated to Savitribai Phule Pune University, Pune-India \\ pawanict@gmail.com
}

Received 30 August 2015 / Accepted 5 October 2015

\begin{abstract}
A simple, efficient and cost effective process has been developed for the synthesis of alicyclic $\alpha$-iodo acids/esters using molecular iodine as a source of iodine under mild reaction conditions. The process is applicable to various alicyclic acids tested and provides good to excellent yields of the desired product. The developed protocol is advantageous with regards to ease in handling the source of iodine and simple work-up procedure.
\end{abstract}

Keywords: $\alpha$-Iodination, alicyclic acid, ester, iodine.

\section{Introduction}

Synthesis of $\alpha$-halo carbonyl compounds are among the most important processes in organic chemistry as they contribute to be the key intermediate in synthesis of various pharmaceutical compounds ${ }^{1-3}$. The $\alpha$-halogenation of carbonyl compounds like aldehyde and ketones are well studied reactions ${ }^{4-12}$, however, $\alpha$-halogenation of acids are comparatively ignored despite of its potential application as drug intermediate in many API's. There are many scientific reports on $\alpha$-bromination of aliphatic acids ${ }^{13-18}$, but $\alpha$-iodination of aliphatic acids are not explored to their capacity.

To the best of our knowledge till date, there is no report on $\alpha$-iodination of alicyclic acids. Therefore, there is need to develop a method for the $\alpha$-iodination of alicyclic acids. Recently, we have reported a simple and efficient methodology for the $\alpha$-bromination of alicyclic acids to yield $\alpha$-bromo acids/esters ${ }^{19}$. In continuation of our work on $\alpha$-halogenation of alicyclic compounds, in current article we are reporting a simple, efficient and green methodology for $\alpha$-iodination of alicyclic acids for the first time. Excellent yields of desired $\alpha$-iodo acids/esters were obtained under optimized reaction conditions (Scheme 1).

\section{Experimental}

All chemicals were purchased from Sigma-Aldrich and S. D. Fine Chemicals Ltd. with their highest purity available. The chemicals were used without any further purification. The selected products are well characterized by using analytical techniques like ${ }^{1} \mathrm{H}$ NMR, (Varian $400 \mathrm{MHz}$ ), and MS-MS (Varian Inc, 410 Prostar $500 \mathrm{MS}$ ). 


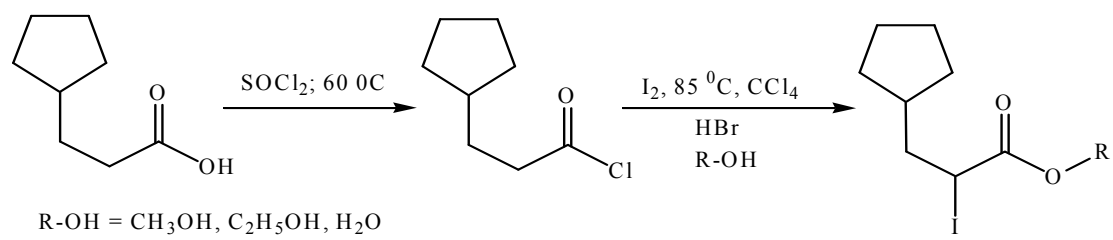

Scheme 1. $\alpha$-Iodination of alicyclic acids

\section{General procedure for the $\alpha$-iodination of alicyclic acid}

To a $50 \mathrm{~mL}$ RBF was added the alicyclic acid $(2.0 \mathrm{mmol})$, and thionyl chloride $(8.0 \mathrm{mmol})$. The mixture was heated at $60{ }^{\circ} \mathrm{C}$ and the progress of reaction was monitored by TLC, reaction was found to complete in $1 \mathrm{~h}$. The reaction mixture was cooled to room temperature and then to $0-5{ }^{\circ} \mathrm{C}$, then at $0-5{ }^{\circ} \mathrm{C}$, charged molecular iodine $(2.4 \mathrm{mmol}), \mathrm{HBr}$ (4-5 drops) and $\mathrm{CCl}_{4}(20.0 \mathrm{~mL})$. The reaction mixture was refluxed and reaction was monitored using TLC. The reaction was found to complete in 2.5 to $3 \mathrm{~h}$. After completion of reaction as revealed by TLC analysis, reaction mixture was again cooled to $0-5{ }^{\circ} \mathrm{C}$ and $25.0 \mathrm{~mL}$ of suitable solvent (alcohol / water) was added to it. The mixture was stirred for $30 \mathrm{~min}$ at $0-5{ }^{\circ} \mathrm{C}$ to obtained desired product. Finally, solvent was removed under reduced pressure. The residue obtained was purified by column chromatography (Silica gel, 60-120 mesh; petroleum ether / ethyl acetate) to afford the desired product. Analytical and spectral data of selected compounds are given below.

\section{3-Cyclopentyl-2-iodo-propionic acid methyl ester (Table 1, entry 1)}

Liquid, Yield: $95 \%(536 \mathrm{mg}) .{ }^{1} \mathrm{H}$ NMR $\left(400 \mathrm{MHz}, \mathrm{CDCl}_{3}, 25{ }^{\circ} \mathrm{C}\right): \delta=4.38-4.43(\mathrm{t}, J=7.6$ $\mathrm{Hz}, 1 \mathrm{H}), 3.79$ (s, 3H), 2.03-2.14 (m, 2H), 1.04-1.80 (m, 9H) ppm. MS-MS (ESI $\left.{ }^{-}\right) \mathrm{m} / \mathrm{z}$ calculated for $(\mathrm{M}+1): 283.12$; found $(\mathrm{M}+1): 283.10$.

\section{3-Cyclopentyl-2-iodo-propionic acid (Table 1, entry 3)}

Liquid, Yield: $87 \%(0.470 \mathrm{mg}) .{ }^{1} \mathrm{H}$ NMR $\left(400 \mathrm{MHz}, \mathrm{CDCl}_{3}, 25^{\circ} \mathrm{C}\right): \delta=10.70(\mathrm{~s}, 3 \mathrm{H}), 4.44-$ $4.47(\mathrm{t}, J=7.8 \mathrm{~Hz}, 1 \mathrm{H}), 2.06-2.16(\mathrm{~m}, 2 \mathrm{H}), 1.08-1.84(\mathrm{~m}, 9 \mathrm{H}) \mathrm{ppm}$. MS-MS (ESI $\left.{ }^{-}\right) \mathrm{m} / \mathrm{z}$ calculated for $(\mathrm{M}+1)$ : 269.10; found $(\mathrm{M}+1): 270.01$.

\section{Results and Discussion}

Initially, reaction of cyclopentyl propionic acid (CPPA) was chosen as model reaction. The desired product was achieved in one step without isolation of any intermediate. Initially, CPPA is converted into its acid chloride derivative using thionyl chloride as a chlorinating agent. The acid chloride so obtained was then subjected to iodination at $\alpha$-position and finally converted into its methyl ester by treating with methanol. The product, $\alpha$-iodo methyl ester was then isolated, purified and analyzed. The influence of various parameters such as temperature, solvent, acid reagent were examined on the model reaction (Table 1). The influence of solvents on $\alpha$-iodination of CPPA was investigated (Table 1, entries 1-4). Solvents like $\mathrm{CCl}_{4}$ (95\%), $\mathrm{CH}_{2} \mathrm{Cl}_{2}(57 \%) \mathrm{CHCl}_{3}(28 \%)$ and toluene (43\%) were screened. It was observed that reaction gave better results with $\mathrm{CCl}_{4}$ as solvent. Next, we investigated effect of acid on rate of reaction. Actually, initially when we did same reaction without any acid reagent then there was little amount of product was detected on TLC but we were unable to isolate it. The product formation was observed to be same after many trials, we had confirmed it on GC-MS as well. Then accidently we added few drops of $\mathrm{HBr}$ in reaction and we observed dramatic increase in yield of the product ( $95 \%$, table 1, entry 1). Inspired 
by this result, we then tried reaction with different acids to investigate the role of acid. Among the various acids tested like $\mathrm{HBr}, \mathrm{HCl}, \mathrm{H}_{2} \mathrm{SO}_{4}, \mathrm{ZnCl}_{2}$ (Table 1, entries 1 \& 5-8); $\mathrm{HBr}$ found to furnishes the product with excellent yield ( $95 \%)$.

In order to examine the effect of temperature, reactions were carried out at different temperatures ranging from 50 to $85{ }^{\circ} \mathrm{C}$ (Table 1 , entries $1 \& 9-10$ ). It was observed the under reflux conditions $\left(85^{\circ} \mathrm{C}\right)$ the desired product was obtained with excellent yield. With decrease in temperature the yield of product was found to decrease.

Table 1. Effect of reaction parameters on $\alpha$-iodination of $\mathrm{CPPA}^{\mathrm{a}}$

\begin{tabular}{ccccc}
\hline Entry & Solvent & Temperature, ${ }^{\circ} \mathrm{C}$ & Acid & Yield, $\%^{\mathrm{b}}$ \\
\hline \multicolumn{5}{c}{ Effect of solvent } \\
\hline 1 & $\mathrm{CCl}_{4}$ & Reflux & $\mathrm{HBr}$ & 95 \\
3 & $\mathrm{CH}_{2} \mathrm{Cl}_{2}$ & Reflux & $\mathrm{HBr}$ & 57 \\
4 & $\mathrm{CHCl}_{3}$ & Reflux & $\mathrm{HBr}$ & 28 \\
& Toluene & Reflux & $\mathrm{HBr}$ & 43 \\
5 & & Effect of acid & Without acid & Non-isolable \\
6 & $\mathrm{CCl}_{4}$ & 85 & $\mathrm{HCl}$ & 36 \\
7 & $\mathrm{CCl}_{4}$ & 85 & $\mathrm{H}_{2} \mathrm{SO}_{4}$ & 52 \\
8 & $\mathrm{CCl}_{4}$ & 85 & $\mathrm{ZnCl}$ & $22^{*}$ \\
9 & $\mathrm{CCl}_{4}$ & 85 & & 76 \\
10 & $\mathrm{CCl}_{4}$ & Effect of temperature & $\mathrm{HBr}$ & 62 \\
\hline
\end{tabular}

${ }^{a}$ Reaction conditions: CPPA (2 mmol), thionyl chloride ( 8 mmol), iodine (2.4 mmol), acid (4-5 drops), solvent $(20 \mathrm{~mL}), 3 \mathrm{~h}$, methanol $(25 \mathrm{~mL}) .{ }^{b}$ isolated yield. ${ }^{*}$ Gummy mass was obtained.

The optimized reaction conditions were CPPA $(2 \mathrm{mmol})$, thionyl chloride $(8 \mathrm{mmol})$, iodine (2.4 mmol), $\mathrm{HBr}\left(4-5\right.$ drops), $\mathrm{CCL}_{4}(20 \mathrm{ml})$, at $85{ }^{\circ} \mathrm{C}$ for $3 \mathrm{~h}$. These conditions were then applied to the $\alpha$-iodination of different alicyclic acids to get various $\alpha$-iodo esters $/$ acids as products (Table 2).

Table 2. $\alpha$-Iodination of various alicyclic acids ${ }^{\mathrm{a}}$

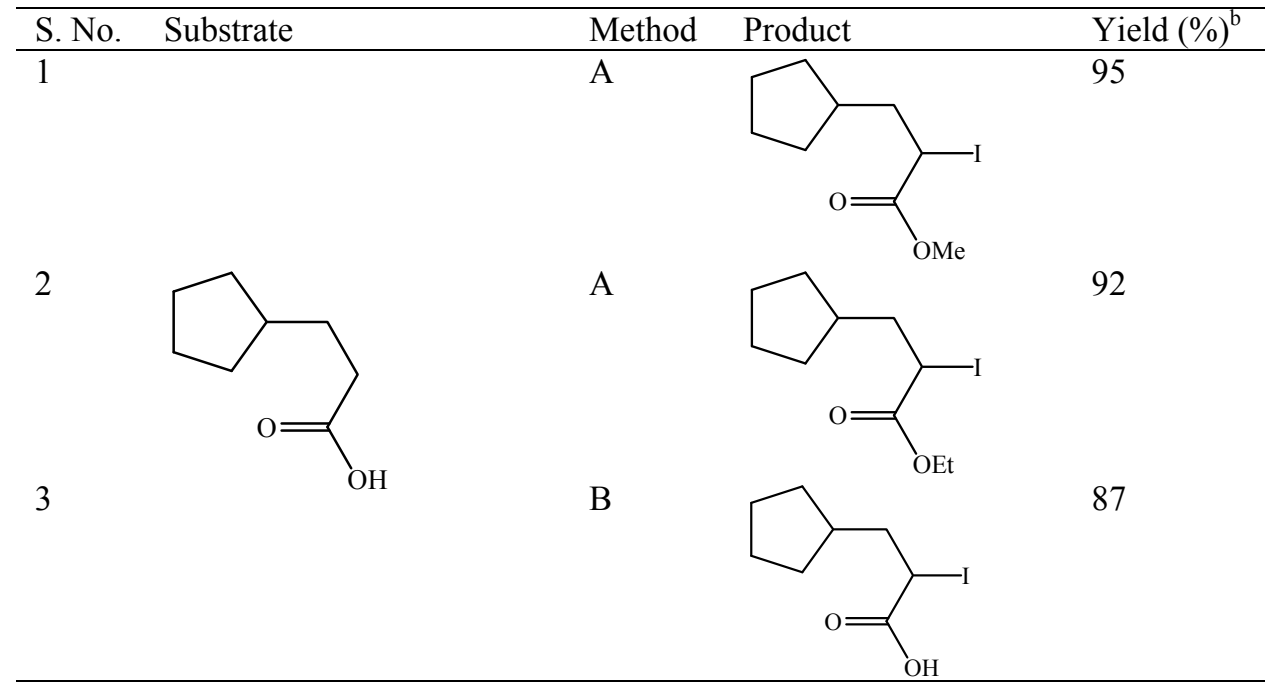




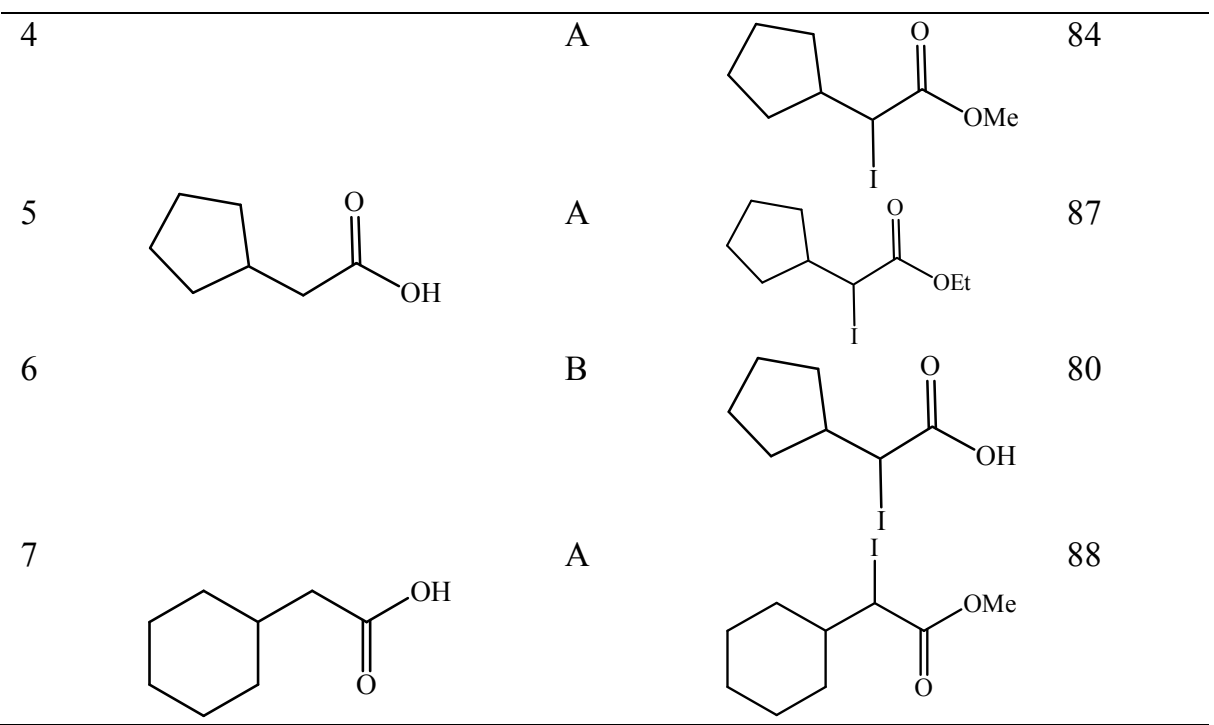

${ }^{a}$ Reaction conditions: Alicyclic acid (2 mmol), thionyl chloride (8 mmol), iodine (2.4 mmol), $\mathrm{HBr}$ (4-5 drops), CCl $4(20 \mathrm{~mL})$, time: $2.5-3 \mathrm{~h}$, temperature: $85^{\circ} \mathrm{C}$, alcohol / water $(25 \mathrm{~mL}) .{ }^{b}$ Isolated yield.

CPPA reacts efficiently under optimized reaction conditions, providing $95 \%$ yield of the desired methyl ester product (Table 2, entry 1) when reaction was quenched with methanol. When reaction of CPPA was ended with ethanol and water, $\alpha$-iodo ethyl ester (92 $\%)$ and $\alpha$-iodo acid (87\%) were obtained respectively (Table 2, entries 2-3). Next, we investigated reaction of cyclopentyl acetic acid (CPAA) to yield $\alpha$-iodo products (Table 2 , entries 4-6). Under optimized reaction conditions CPAA furnishes different products with good to excellent yields [ $\alpha$-iodo methyl ester $(84 \%), \alpha$-iodo ethyl ester $(87 \%)$ and $\alpha$-iodo CPAA (80\%)]. Encouraged by these results, we next examined reaction of cyclohexyl acetic acid (CHAA) under optimized reaction conditions. CHAA founds to yield desired methyl ester product in $88 \%$ (Table 2, entry 7 ).

\section{Conclusion}

We have developed a simple and efficient methodology for the effective synthesis of alicyclic $\alpha$-iodo esters / acids using molecular iodine as an iodinating agent. The reaction was optimized with respect to various parameters and could be use for the synthesis of different alicyclic $\alpha$-iodo esters / acids, affording good to excellent yields of the desired products, demonstrating the broad application of developed methodology. The notable advantages offered by this method are simple operation, good yield of products, and cost effectiveness thus making the process economically feasible.

\section{References}

1. Ji S J, Takahashi E, Takahashi T T and Horiuchi C A, Tetrahedron Lett., 1999, 40(52), 9263-9266; DOI:10.1016/S0040-4039(99)02010-9

2. Boyer J H and Natesh A, Synthesis, 1988, 980-981; DOI:10.1055/s-1988-27774

3. Corbett, et al. US patent, US 2002/0103241 A1

4. Podgorsek A, Stavber S, Zupan M and Iskra J, Green Chem., 2007, 9, 1212-1218; DOI:10.1039/B707065A 
5. Lee J C, Kim J, Park H J, Kwag B and Lee B B, Bull Korean Chem Soc., 2010, 31(5), 1385; DOI:10.5012/bkcs.2010.31.5.1385

6. Galligan M J, Akula R and Ibrahim H, Org Lett., 2014, 16(2), 600-603; DOI:10.1021/ol403504z

7. Harpp D N, Bao L Q, Black C J and Smith R A, J Org Chem., 1975, 40(23), 34203427; DOI:10.1021/jo00911a026

8. Akula R, Galligan M J and Ibrahim H, Synthesis, 2011, 347-351; DOI:10.1055/s0030-1258367

9. Lee J C, Park J Y, Yoon S Y, Bae Y H and Lee S J, Tetrahedron Lett., 2004, 45(1), 191-193; DOI:10.1016/j.tetlet.2003.10.133

10. Terentev A O, Khodykin S V, Krylov I B, Ogibin Y N and Nikishin G I, Synthesis, 2006, 1087-1092; DOI:10.1055/s-2006-926386

11. Pravst L, Zupan M and Stavber S, Tetrahedron, 2008, 64(22), 5191-5199; DOI:10.1016/j.tet.2008.03.048

12. Kirihara M, Ogawa S, Noguchi T, Okubo K, Monma Y, Shimizu I, Shimosaki R, Hatano A and Hirai Y, Synlett, 2006, 2287-2289; DOI:10.1055/s-2006-948207

13. Carpino L A, McAdams L V, Org Synth., 1988, 6, 403.

14. Thomas R M and Mamuzic R I, US patent, US, 1972/3661947.

15. Shaw B W, J Chem Soc Trans., 1923, 123, 2233-2240; DOI:10.1039/CT9232302233

16. Harpp D N and Gleason G J, Tetrahedron Lett., 1970, 39, 3431.

17. Allen F C and Kalm M, J Organic Syntheses, 1963, 4, 616.

18. Yogata Y, Sugimoto T, J Org Chem., 1978, 43(19), 3684-3687; DOI:10.1021/jo00413a009

19. Tambade P J, J Applicable Chem., 2014, 3(6), 2644-2647. 